\title{
Cierre percutáneo de defecto tipo Gerbode en un niño de 3 años tras cirugía de Bentall
}

\author{
Juan Manuel Carretero Ballón \\ Freddy Prada \\ Joan Sánchez de Toledo
}

Unidad de Cardiología Pediátrica. Hospital Sant Joan de Deu. Esplugues Llobregat

Recibido: 18/08/2019

Aceptado: 04/01/2020

En línea:02/03/2020

Citar como: Carretero-Ballón JM, Prada F, Sánchez-de Toledo J. Cierre percutáneo de defecto tipo Gerbode en un niño de 3 años tras cirugía de Bentall. Rev Ecocar Pract (RETIC). 2020 (Mar); 3 (1): 23-26. doi: 10.37615/retic.v3n1a6

Cite this as: Carretero-Ballón JM, Prada F, Sánchez-de Toledo J. Percutaneous closure of Gerbode-type defect in a 3-year-old boy after Bentall surgery. Rev Ecocar Pract (RETIC). 2020 (Mar); 3 (1): 23-26. doi: 10.37615/retic.v3n1a6.

\begin{tabular}{l} 
Palabras clave \\
\hline$\triangleright$ Defecto tipo Gerbode \\
$\triangleright$ Complicación de la cirugía \\
de Bentall \\
$\triangleright$ Cierre percutáneo \\
de Gerbode
\end{tabular}

Keywords

$\triangleright$ Gerbode defect

$\triangleright$ Bentall surgery complication

$\triangleright$ Transcatheter Gerbode defect closure

\section{Presentación del caso}

Se presenta el caso de un niño de 3 años que fue diagnosticado de dilatación aneurismática de la aorta. Entre sus antecedentes personales presentaba retraso global del desarrollo, artrogriposis congénita neonatal múltiple con pies equinos y rótulas luxadas, fisura palatina intervenida a los 9 meses y cirugía de ductus arterioso a los 10 días de vida, cirugía en la que se detectó la presencia de un aneurisma de aorta. No tenía historia familiar remarcable, con unos padres sanos procedentes de Perú, que residían en España desde hace 1 año y no tenían otros hijos.

En la exploración clínica destaca un fenotipo peculiar con hipertelorismo, artrogriposis de manos y pies, gran hiperlaxitud, tórax carinatum, subluxación de rótulas y genu recurvatum. En la auscultación cardíaca destacaba un soplo holodiastólico en foco aórtico.

La ecocardiografía mostró una dilatación aneurismática de la raíz aórtica (raíz aórtica de 23 mm, Z-score +6,8; senos de Valsalva 48 mm, Z-score +10,1; unión sinotubular $31 \mathrm{~mm}$, Z-score + 6,6 y aorta ascendente de $19 \mathrm{~mm}$ ) y una válvula aórtica tricúspide con insuficiencia moderada. En la valoración del ventrículo izquierdo se obtuvo un diámetro telediastólico de $35 \mathrm{~mm}(Z$-score +1) y un diámetro telesistólico de 26 mm (Z-score +2,2) con FE 56\%.

\section{Correspondencia}

Juan Manuel Carretero Ballón

jcarretero@sjdhospitalbarcelona.org

\begin{abstract}
El defecto de Gerbode, es decir, la comunicación entre el ventrículo izquierdo y la aurícula derecha es un vila protésica.
\end{abstract}

La angiotomografía computarizada mostró un aneurisma de raíz de aorta de $50,3 \mathrm{~mm}$ en proyección de doble oblicuidad a nivel de senos de Valsalva, que se originaba en la región valvular y se extendía hasta la aorta ascendente, sin afectación del arco aórtico ni de los troncos supraaórticos (Figura 1). La raíz aórtica en el plano valvular mide $46,4 \mathrm{~mm}$, la unión sinotubular $32,8 \mathrm{~mm}$ y la aorta ascendente $19,3 \mathrm{~mm}$.

El estudio oftalmológico descartó anomalías y en el estudio genético se encontró una duplicación de $507 \mathrm{~Kb}$ de la banda cromosómica 6 p25.3 (794273_1301623) x 3. Esta alteración se considera como una variante de significado incierto. Se inició tratamiento con losartán y se decidió la cirugía ante el peligro de complicación severa dada la masiva dilatación de la aorta.

Se realizó una cirugía de Bentall-De Bono con reimplantación de coronarias y prótesis mecánica de $23 \mathrm{~mm}$ dada la insuficiencia aórtica.

El postoperatorio cursó con episodios de taquicardia supraventricular que cedieron con maniobras vagales y tras iniciar tratamiento con betabloqueantes. En el séptimo día postoperatorio se detectó un soplo holosistólico llamativo y la radiografía de tórax mostró una cardiomegalia moderada. La ecocardiografía identificó un shunt de $5 \mathrm{~mm}$ de diámetro desde el ventrículo izquierdo (VI) a la 
aurícula derecha (AD) con dilatación de la AD (Figura 2, Vídeo 1 y Vídeo 2) e hipertensión pulmonar moderada.

Se indicó el cierre percutáneo del defecto. El defecto se cruzó de manera anterógrada desde la $A D$ a la aurícula izquierda (Al) a través de un pequeño foramen oval y luego desde el VI se sondó el defecto hacia la AD con un catéter derecho 4F Judkins y una guía curva de Terumo 0,035". Se estableció un asa venovenosa y se exteriorizó una guía de intercambio a través de la vena yugular derecha. Se introdujo una vaina de liberación 5F Amplatzer ${ }^{\circledast}$ desde la vena yugular derecha, y la punta de la vaina se colocó en el VI. El tamaño medido del defecto era de $5 \mathrm{~mm}$ en la fase telediastólica y la distancia desde el defecto a los discos protésicos medía $10 \mathrm{~mm}$.

Se hizo avanzar un dispositivo oclusor Amplatzer ${ }^{\circledast}$ Duct Occluder II (ADO) de $5 \times 6 \mathrm{~mm}$ a través de la vaina y bajo control de ecocardiografía transesofágica y escopia se liberó el primer disco de retención del oclusor en el VI y posteriormente la vaina y el primer disco se retiraron lentamente como una unidad hasta el defecto con cuidado para garantizar que no atrapara la válvula aórtica. La parte central del dispositivo ocluyó el defecto y, luego, se desplegó el disco proximal (Figura 3). La escopia y la ecocardiografía transesofágica mostraron que el dispositivo no interfería con el movimiento de la válvula protésica, no comprometía la valva tricúspide y no había defecto residual (Figura 3, Vídeo 3 a Vídeo 7).

\section{Estudio por imagen}

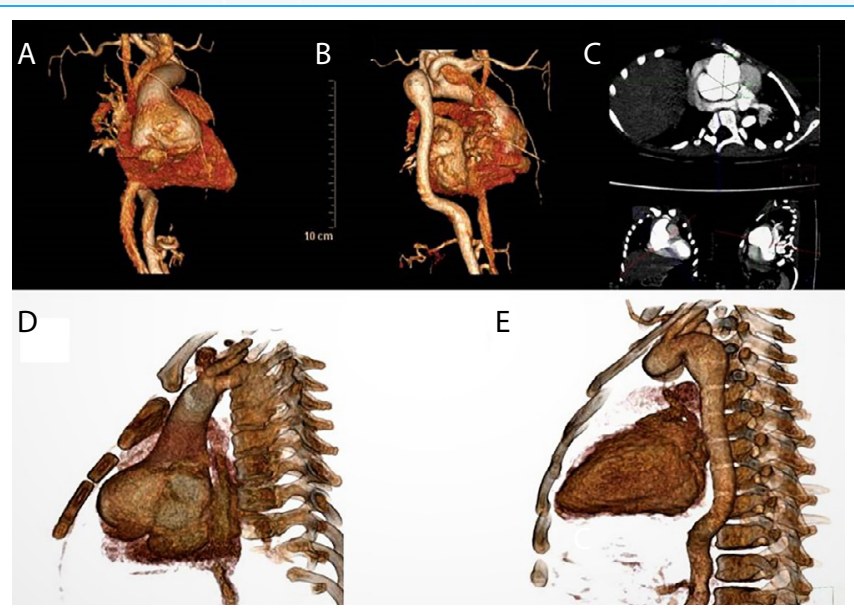

Figura 1. Angio-TC de aorta. A: reconstrucción tridimensional centrada en la raíz aórtica; $\mathbf{B}$ : reconstrucción tridimensional centrada en la aorta descendente; C: imágenes axiales a nivel del aneurisma; D: posprocesado de la imagen tridimensional centrado en la raíz aórtica; E: posprocesado de la imagen tridimensional centrado en la aorta descendente
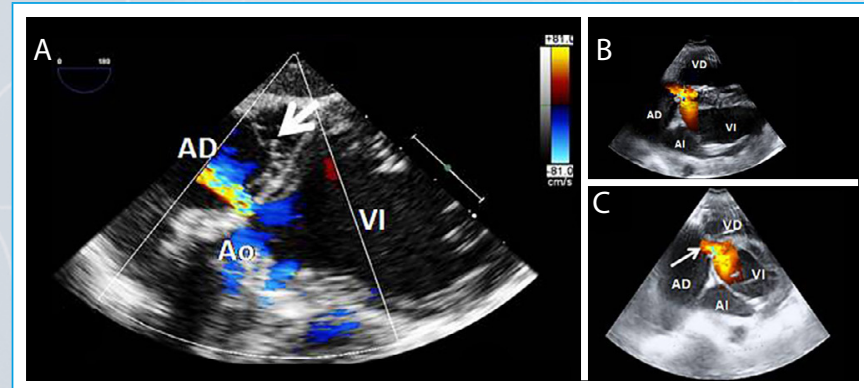

Figura 2. Imágenes de la ecocardiografía realizada tras la cirugía de Bentall que muestran la comunicación entre el VI y la AD

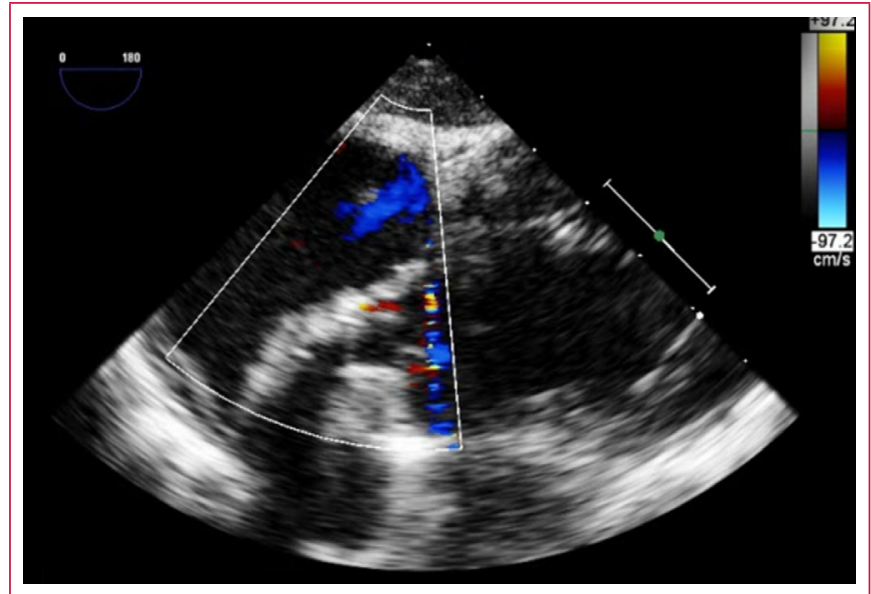

Vídeo 1. Defecto tipo Gerbode. El plano ecocardiográfico corresponde al de la Figura 2A

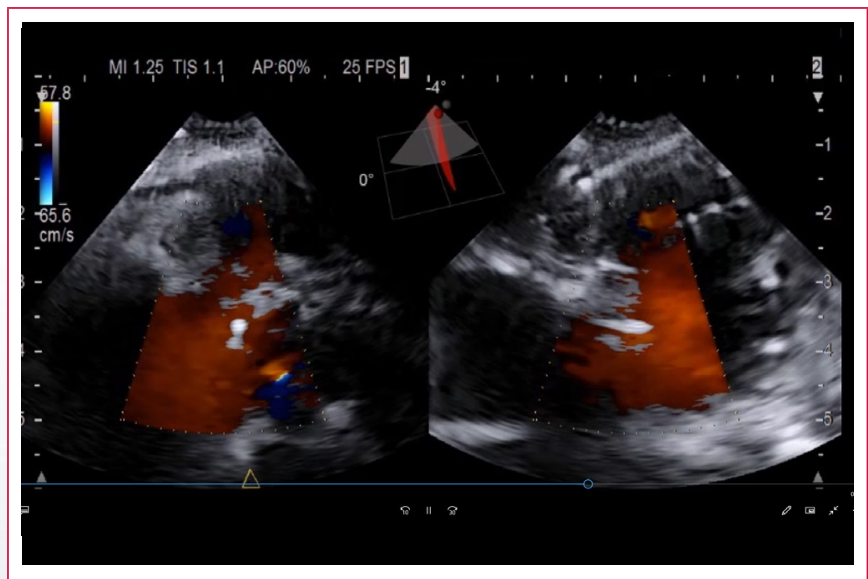

Vídeo 2. Defecto tipo Gerbode. El plano ecocardiográfico corresponde al de la Figura 2B

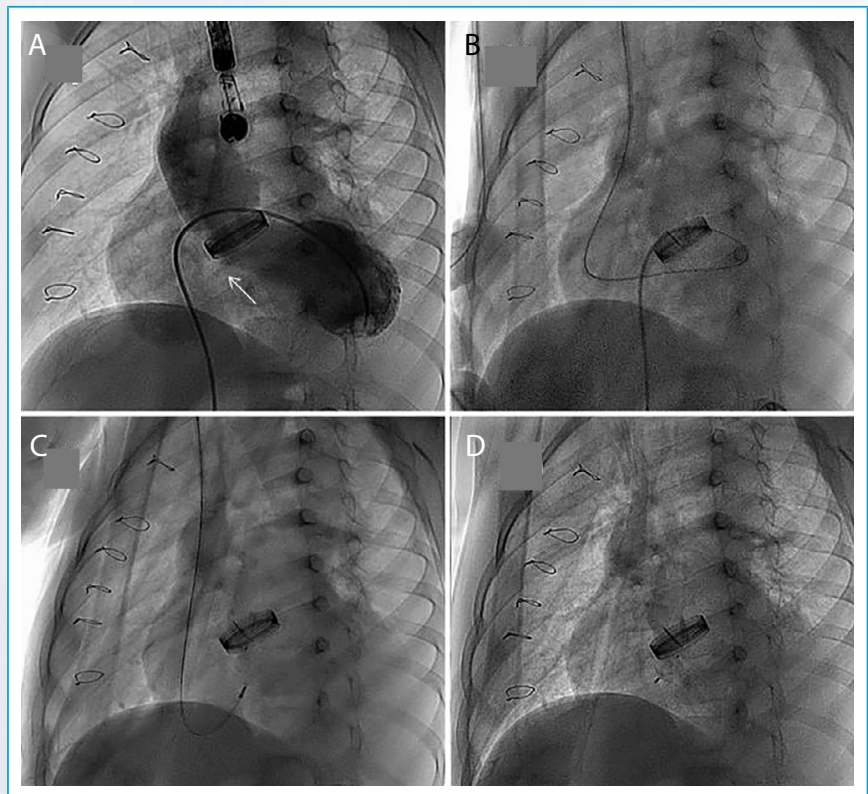

Figura 3. Pasos del procedimiento de cierre percutáneo. A: ventriculografía de opacificación rápida de la $\mathrm{AD}$ tras inyectar contraste en el Vl; $\mathbf{B}$ : guía realizando un asa venovenosa para soporte y colocación del dispositivo; C: liberación del dispositivo; D: posición final 


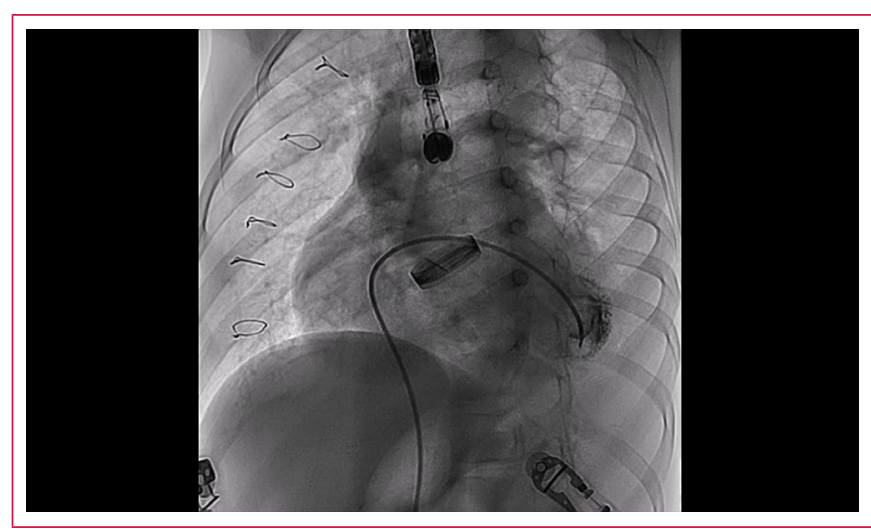

Vídeo 3. Imagen de la ventriculografía. La imagen corresponde a la Figura $3 \mathrm{~A}$

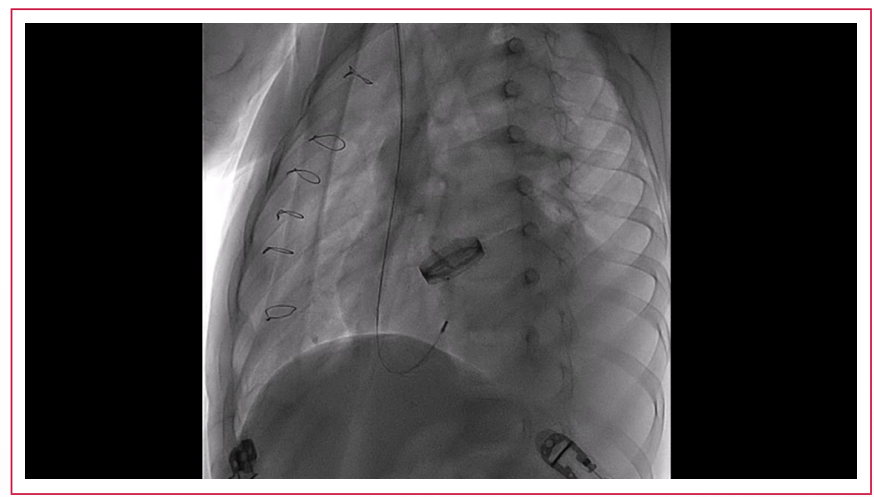

Vídeo 4. Liberación de los discos del dispositivo

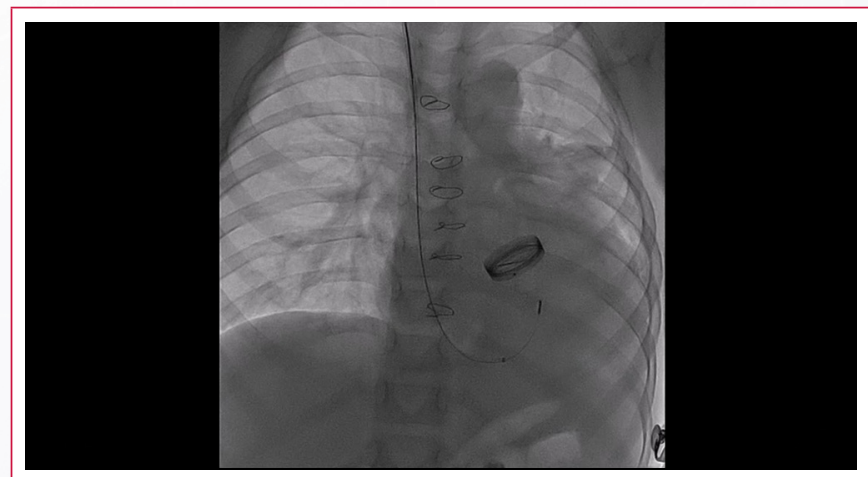

Vídeo 5. Suelta del dispositivo. Corresponde a la Figura 3C

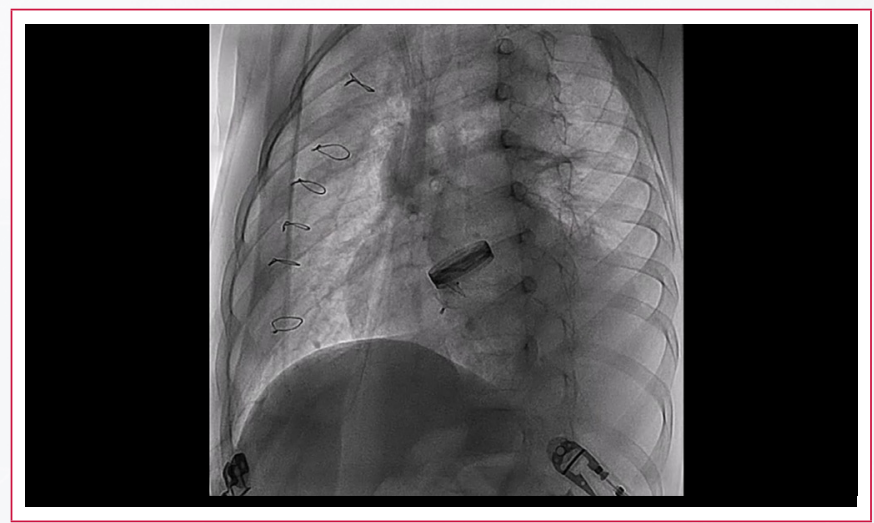

Vídeo 6. Posición final del dispositivo. Se puede apreciar que los discos de la prótesis se mueven sin alteraciones. Corresponde a la Figura 3D

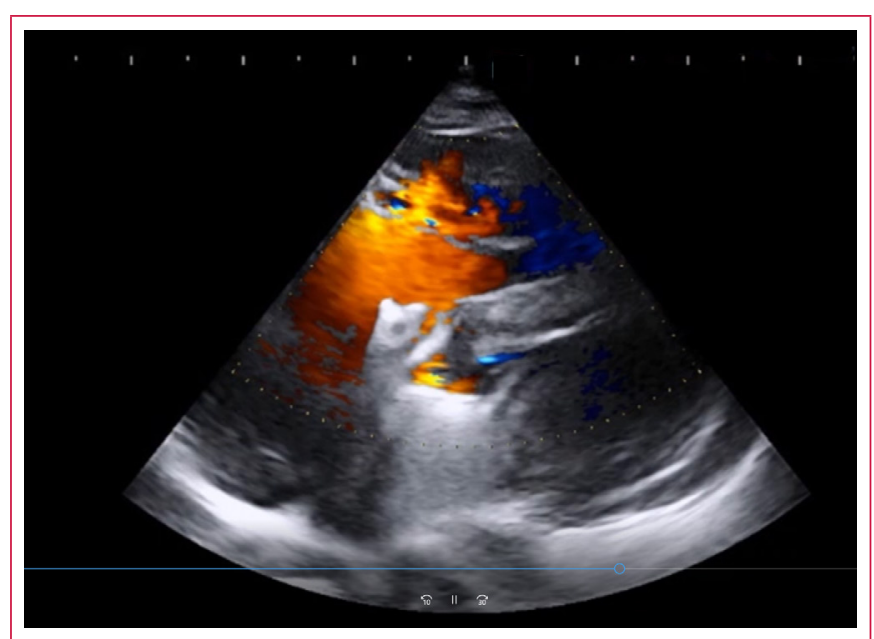

Vídeo 7. Ecocardiografía de control con el dispositivo de cierre colocado de forma estable y sin defecto residual apreciable

\section{Discusión}

Los defectos de Gerbode son comunicaciones entre el VI y la $A D^{(1)}$. Son infrecuentes y pueden ser congénitos $(0,08 \%)$ o adquiridos. La clasificación anatómica más extendida es la que los clasifica dependiendo de su localización en relación con la inserción del velo septal de la válvula tricúspide. El defecto puede estar por encima (tipo I o directo), por debajo de la válvula tricúspide (tipo ॥ o indirecto que con frecuencia se confunde con regurgitación tricúspide) o una combinación de ambos tipos (tipo III) (2). La ecocardiografía transtorácica en una vista apical de cuatro cámaras con el Doppler color permite clasificar el tipo de defecto.

Las formas adquiridas se deben principalmente a endocarditis, traumatismo, infarto de miocardio y complicaciones posteriores a la cirugía cardíaca, siendo esta última la forma de defecto de Gerbode adquirido más frecuente(3).

Los defectos de Gerbode tanto congénitos como adquiridos se han corregido tradicionalmente de forma quirúrgica. Algunos autores defienden el cierre de todos los defectos de Gerbode, independientemente de su tamaño, para evitar la endocarditis infecciosa ${ }^{(4)}$. Se ha demostrado que el cierre quirúrgico es factible con un buen resultado, aunque en un estudio donde se recopilan los defectos tratados de forma quirúrgica como complicación tras una cirugía cardíaca los resultados de éxito son moderados con un 75\% de éxito ${ }^{(3)}$. Quizá en estos casos complejos que en muchas ocasiones son candidatos quirúrgicos de alto riesgo debido a reemplazo valvular previo, edad avanzada, anticoagulación y comorbilidades múltiples, el uso de técnicas de cierre percutáneo tenga un papel destacable $e^{(2,3)}$.

Se opta por el cierre percutáneo al tener experiencia en el cierre de las comunicaciones interventriculares (CIV) perimembranosas con el oclusor ADO II y porque la técnica para cerrar los defectos de Gerbode es la misma que para el cierre de la CIV perimembranosa ${ }^{(5)}$. Se elige este dispositivo porque tiene un bajo perfil, por lo que necesita una vaina más pequeña que otros dispositivos, lo que supone una gran ventaja cuando se trata de pacientes pediátricos. El cilindro central encaja perfectamente en el defecto y los discos de retención blandos a ambos lados, sin material de poliéster, no inciden en la aorta, la mitral o válvula tricúspide. Por ello, este dispositivo parece ser un dispositivo ideal para el cierre de los defectos tipo Gerbode.

Así mismo, se elige un diámetro de dispositivo que tenía el mismo tamaño que el del defecto. De acuerdo con la experiencia previa de los autores con el 
cierre de la CIV y con la bibliografía, se elige un tamaño de dispositivo entre 0-1 mm mayor que el diámetro del defecto(5). La mayor serie publicada de cierre de defectos de Gerbode congénitos también utiliza esta regla a la hora de escoger el tamaño del dispositivo(6). La ecocardiografía transesofágica durante e procedimiento no mostró problemas con las estructuras adyacentes y es una herramienta fundamental para la monitorización del cierre de estos defectos.

\section{Conclusión}

El cierre percutáneo de los defectos de Gerbode es una alternativa al cierre quirúrgico y debe considerarse dentro del arsenal terapéutico en este tipo de defectos incluso en niños pequeños. El dispositivo oclusor ADO II es un dispositivo seguro y efectivo y por su estructura puede ser un dispositivo ideal para el cierre de este tipo de defectos.

\section{Ideas para recordar}

- El defecto de tipo Gerbode es una complicación que se debe incluir en el diagnóstico diferencial en pacientes sometidos a cirugía cardíaca que no se están recuperando normalmente.

- En pacientes con defectos de tipo Gerbode la ecocardiografía transesofágica desempeña un papel importante en el diagnóstico, la selección del tamaño del dispositivo y, especialmente, durante el despliegue del dispositivo.

\section{Bibliografía}

1. Gerbode F, Hultgren H, Melrose D, Osborn J. Syndrome of left ventricularright atrial shunt; successful surgical repair of defect in five cases,with observation of bradycardia on closure. Ann Surg 1958; 148: 433-446.

2. Saker E, Bahri GN, Montalbano MJ, et al. Gerbode defect: A comprehensive review of its history, anatomy, embryology, pathophysiology, diagnosis, and treatment. J Saudi Heart Assoc 2017; 29 (4): 283-292.

3. Sinisalo JP, Sreeram N, Jokinen E, Qureshi SA. Acquired left ventricular-right atrium shunts. Eur J Cardiothorac Surg 2011; 39 (4): 500-506.

4. Yacoub MH, Mansur A, Towers M, Westbury H. Bacterial endocarditis complicating left ventricle to right atrium communication. Br J Dis Chest 1972; 66: 78-82.

5. Esmaeili A, Behnke-Hall K, Schrewe R, Schranz D. Percutaneous closure of perimembranous ventricular septal defects utilizing almost ideal Amplatzer Duct Occluder II: Why limitation in sizes? Congenit Heart Dis 2019; 14 (3): 389-395.

6. Vijayalakshmi IB, NatrajSetty HS, Chitra N, Manjunath CN. Amplatzer duct occluder II for closure of congenital Gerbode defects. Catheter CardiovasC Interv 2015; 86 (6): 1057-1062. 